\title{
Corrosion Inhibition
}

\author{
Robert Lindsay ${ }^{1, *(\mathbb{D})}$ and Anton Kokalj $2, *(\mathbb{D})$ \\ 1 Corrosion and Protection Centre, School of Materials, The University of Manchester, Sackville Street, \\ Manchester M13 9PL, UK \\ 2 Department of Physical and Organic Chemistry, Jožef Stefan Institute, Jamova 39, SI-1000 Ljubljana, Slovenia \\ * Correspondence: robert.lindsay@manchester.ac.uk (R.L.); tone.kokalj@ijs.si (A.K.); \\ Tel.: +44-161-306-4824 (R.L.); +386-1-477-3523 (A.K.)
}

Received: 8 October 2018; Accepted: 9 October 2018; Published: 12 October 2018

check for updates

For more than a century, corrosion inhibitors have been added to aggressive environments to protect metallic materials. Currently, they are integral to structural integrity strategies across a wide range of industrial sectors, e.g., oil production, chemical processing, and aerospace. On this basis, there is significant ongoing research in this area seeking to optimise the performance of corrosion inhibitors, ranging from development of new active species to gaining mechanistic understanding. The eight articles published in this Special Issue showcase some of this work, encompassing both experimental and modelling effort.

Concerning experimental work, Wood and Clarke [1] provide an excellent review of the application of neutron reflectometry for studying corrosion and corrosion inhibition. They demonstrate the potential of this approach for characterising pertinent interfaces in situ at the atomic scale, and describe the advantages and limitations of such measurements. Arkhipushkin et al. [2] report their recent work on the inhibition of brass $(\mathrm{Cu} / \mathrm{Sn}$ alloy) through the addition of a triazole-type compound to aqueous sodium chloride. Employing a combination of electrochemical measurements and X-ray photoelectron spectroscopy (XPS), they are able to gain insight into the functionality of the inhibitive species. Driven by the imperative to remove chromate from coatings, the experimental study of Rodič et al. [3] focuses on the impact of cerium ions on the structure and corrosion resistance of $\mathrm{Si} / \mathrm{Zr}$-based sol-gel coatings applied to aluminium. A combination of electrochemical probes and interfacial characterisation reveal the benefits of cerium addition through improving both barrier and active inhibition properties.

Turning to modelling, two articles by Gustinčič and Kokalj $[4,5]$ demonstrate the power of the ab initio density functional theory (DFT) bottom-up approach to scrutinise the bonding of corrosion inhibitors with oxidised metal surfaces. Although the inhibitor-surface bonding itself is not synonymous with corrosion inhibition, it nevertheless represents one aspect towards an atomic-scale understanding of corrosion protection mechanisms. Such work enables one to systematically address specific aspects of corrosion inhibitor interaction, and so extract key phenomena and trends. For example, the importance of dissociative adsorption (loss of $\mathrm{H}$ ) was examined for the binding of azole compounds to oxidised copper [4]. In their second article they utilise the DFT calculated data and apply an ab initio thermodynamics framework to shed light onto the stability of various surface structures and molecular phases [5]. In another DFT study, Cornette et al. [6] show the potential importance of considering the substrate as an active component in corrosion modelling through examining the segregation of $\mathrm{Cu}$ in $\mathrm{Cu}-\mathrm{Al}$ alloys terminated by a passive oxide film, and illuminate the effect of such segregation on the electronic properties of the surface (e.g., work function and band gap).

The final two articles are concerned with increasing the efficiency of the corrosion inhibitor selection process. Taylor et al. [7] discuss the development of computationally fast cluster-type DFT calculations for predicting key thermodynamic parameters in the context of corrosion inhibition. The goal is to facilitate more rapid, but reliable, computer-based screening of candidate corrosion 
inhibitor molecules. Winkler [8] reviews efforts to date to exploit high-throughput testing in combination with machine learning methods to identify high-performing candidate molecules. As indicated, a primary motivation for this work is to discover more environmentally acceptable corrosion inhibitors, which is an increasingly important consideration for both technical suppliers and users. He further casts doubt on many reported correlations between molecular properties derived from quantum chemical calculations and corrosion inhibition efficiency, because these correlations are based on very small data sets with limited chemical diversity and because these descriptors are not statistically significant enough to be useful.

Conflicts of Interest: The authors declare no conflict of interest.

\section{References}

1. Wood, M.H.; Clarke, S.M. Neutron Reflectometry for Studying Corrosion and Corrosion Inhibition. Metals 2017, 7, 304. [CrossRef]

2. Arkhipushkin, I.A.; Shikhaliev, K.S.; Potapov, A.Y.; Sapronova, L.V.; Kazansky, L.P. Inhibition of Brass (80/20) by 5-Mercaptopentyl-3-Amino-1,2,4-Triazole in Neutral Solutions. Metals 2017, 7, 488. [CrossRef]

3. Rodič, P.; Katić, J.; Korte, D.; Desimone, P.M.; Franko, M.; Ceré, S.M.; Metikoš-Huković, M.; Milošev, I. The Effect of Cerium Ions on the Structure, Porosity and Electrochemical Properties of Si/Zr-Based Hybrid Sol-Gel Coatings Deposited on Aluminum. Metals 2018, 8, 248. [CrossRef]

4. Gustinčič, D.; Kokalj, A. DFT Study of Azole Corrosion Inhibitors on $\mathrm{Cu}_{2} \mathrm{O}$ Model of Oxidized Copper Surfaces: I. Molecule-Surface and Cl-Surface Bonding. Metals 2018, 8, 310. [CrossRef]

5. Gustinčič, D.; Kokalj, A. DFT Study of Azole Corrosion Inhibitors on $\mathrm{Cu}_{2} \mathrm{O}$ Model of Oxidized Copper Surfaces: II. Lateral Interactions and Thermodynamic Stability. Metals 2018, 8, 311. [CrossRef]

6. Cornette, P.; Costa, D.; Marcus, P. DFT Modelling of Cu Segregation in Al-Cu Alloys Covered by an Ultrathin Oxide Film and Possible Links with Passivity. Metals 2017, 7, 366. [CrossRef]

7. Taylor, C.D.; Kurapati, Y.; Mondal, S.K. Interaction of Model Inhibitor Compounds with Minimalist Cluster Representations of Hydroxyl Terminated Metal Oxide Surfaces. Metals 2018, 8, 81. [CrossRef]

8. Winkler, D.A. Predicting the Performance of Organic Corrosion Inhibitors. Metals 2017, 7, 553. [CrossRef]

(C) 2018 by the authors. Licensee MDPI, Basel, Switzerland. This article is an open access article distributed under the terms and conditions of the Creative Commons Attribution (CC BY) license (http:/ / creativecommons.org/licenses/by/4.0/). 